\title{
economics-of-security.eu
}

Seo-Young Cho

\section{Human Trafficking, A Shadow of Migration - Evidence from Germany}

September 2012

Economics of Security Working Paper 76 
Correct citation: Cho, S.-Y. (2012). "Human Trafficking, A Shadow of Migration - Evidence from Germany". Economics of Security Working Paper 76, Berlin: Economics of Security.

First published in 2012

(C) Seo-Young Cho 2012

ISSN: 1868-0488

For further information, please contact:

Economics of Security, c/o Department of Development and Security, DIW Berlin - German Institute for Economic Research, Mohrenstr. 58, 10117 Berlin, Germany.

Tel: $+49(0) 3089789-441$

Email: eusecon@diw.de

Website: www.economics-of-security.eu 


\title{
Human Trafficking, A Shadow of Migration \\ - Evidence from Germany
}

\author{
Seo-Young Cho*
}

September 2012

\begin{abstract}
:
This paper empirically analyzes the causal relationship between migration and human trafficking inflows into Germany during the period between 2001 and 2010. My results suggest that migrant networks, measured by migrant stocks from a specific source country, increase the illicit, exploitative form of migration - human trafficking - from that respective country. However, the network effect varies across different income levels of source countries. The significant, positive effect of migrant networks decreases as the income level increases, and furthermore the effect is insignificant for high income countries.
\end{abstract}

Keywords: Human trafficking; Migration; Network effects

JEL codes: F22, J23, J61

Acknowledgement: The author is grateful with Daniel Focke of the German Federal Criminal Police Office (Bundeskriminalamt) for sharing valuable data used in this study. Also, the author thanks Enrique Ali Fernández Flores for his excellent research assistance and Thea Coventry for her excellent proof-reading.

* Seo-Young Cho is a research fellow at the German Institute for Economic Research (DIWBerlin). She received her Ph.D. from the University of Goettingen in Germany and master from Columbia University in the U.S.

Contact: Telephone: +49 (0)30 89789 307, Fax: +49 (0)30 89789 108, Email: scho@diw.de website: http://www.economics-human-trafficking.net/ 


\section{Introduction}

Migrant networks play an important role in the migration decisions of low-skilled individuals because the networks reduce informational costs on migration (Mckenzie and Rapoport 2007; Palloni et al. 2001; Pedersen et al. 2008). Therefore, the existing migrant networks of a specific source country may induce further migration from that country, particularly by individuals with low skills who may not be able to pursue costly forms of migration. Literature suggests that migrant networks have positive effects on reducing inequality in source countries by providing employment opportunities for the low-skilled (Mckenzie and Rapoport 2007). However, the network effects on the migration of the lowskilled may also have an undesirable effect of pulling human trafficking into destination countries by inducing low-skilled migration, to which most victims of human trafficking belong.

This argument linking migrant networks and human trafficking may be puzzling at first glance. Generally speaking, migrant networks induce further migration because existing migrants can provide information and assistance for new comers, helping them to find a job and settle into the destination country, and therefore the networks may reduce human smuggling or other illegal migration (Danailova-Trainor and Belser 2006). However, at the same time, low-skilled migrants - whom migrant networks arguably disproportionally pull - are susceptible to several problems associated with human trafficking. Firstly, they are more likely to be deceived regarding migration options and working conditions in the destination country. According to the International Organization for Migration (2010), most victims of human trafficking are initially migrants who end up being trafficked on the way to the destination by coercion, fraud, deception or other similar means. Furthermore, established migrant networks may not always function as an information and assistance provider, instead some existing migrants may use inflows of low-skilled migration as an opportunity to make profits by exploiting the new comers. In fact, traffickers are known to target their own nationals. Further, some victims are trafficked by their own relatives and acquaintances, who have already migrated to a destination country (BKA 1999-2010; IOM 2010; UNODC 2006). Secondly, lowskilled migrants are more likely to have difficulties in finding a job with decent payment and conditions in the destination country. Consequently, in order to ensure their livelihoods, 
migrants may take risky employment options that increase the probability of them being trafficked. Such situations are particularly likely to occur, if low-skilled migrants are motivated to migrate by the presence of migrant networks in the destination but the networks do not actually provide specific and persistent help for individual migrants. ${ }^{1}$ This argument leads to a prediction that established migrant networks - consisting of mostly legal migrants - can be a pull factor of illegal and exploitative migration leading to human trafficking. In the literature, Mahmoud and Trebesch (2010) provide micro-evidence supporting this argument that the prevalence of emigration in a household/region increases probabilities of human trafficking because of lower recruitment costs and negative self-selection.

In my study, I test for the above prediction in order to provide empirical evidence on the causal relationship between migrant networks and human trafficking. In doing so, I focus on Germany as it is one of the major destinations countries of trafficking victims (UNODC 2006; US 2012). Furthermore, there is a methodological advantage of using Germany for the analysis: data availability. Germany has published detailed data on human trafficking inflows from various source countries worldwide every year since 1999. In fact, data on human trafficking is extremely scarce (Kangaspunta 2003; Tyldum and Brunovskis 2005) and there are only a few countries in the world which provide annual statistics on human trafficking over a length of time. This problem in data acquisition makes cross-country analysis likely to be biased due to the sample selection issues and, furthermore, the different definitions of human trafficking, which different countries adopt, exacerbate the problem in cross-country comparison (Jakobsson and Kotsadam 2012). Therefore, most existing studies on human trafficking at the macro-level employ an indicator/index reflecting the magnitudes of human trafficking - either dummy or ordinal scores (Akee at al. 2010 a, b; Cho 2012; Cho forthcoming; Cho et al. forthcoming; Jakobsson and Kotsadam 2011; Rao and Presenti 2012), bearing the costs of using imprecise, simplified measurements. On the contrary, the data published by the German Federal Criminal Police Office (Bundeskriminalamt, BKA) provide the numbers of victims and perpetrators of sex trafficking identified in Germany every year. By employing the count data

\footnotetext{
${ }^{1}$ With this respect, Mahmoud and Trebesch (2010) argue that it is likely the case if the quality of migrant networks decreases due to the negative self-selection towards low-skilled migration.
} 
for my analysis, the precision of the estimation results is improved. Also, as the data is collected by a single government, selection biases are reduced and the identical definition of human trafficking is applied, increasing the cross-time comparability of the data. On the other hand, as this analysis focuses on Germany, the findings may be Germany-specific and thus not always applicable to other countries. However, the main findings of this paper on Germany can provide implications for countries sharing economic, institutional, cultural and geographical similarities with Germany - particularly western European and developed countries, which consist of the majority of the destination countries of human trafficking.

In Germany, the patterns of migration and human trafficking share similar features. As seen in figure 3 , the majority of victims of human trafficking come from middle income countries rather than low income countries. Given that poverty and low income is an important push factor of human trafficking (Akee et al. 2010 a, b; Cho 2012; Jakobsson and Kotsadam 2011), the dominant presence of middle income countries among victims appears to be a puzzle. Figure 4 showing the distributions of migrants by the income levels of source countries suggests a tentative explanation to this puzzle by demonstrating a positive association with the patterns of human trafficking. My empirical analysis supports the observation from the descriptive statistics and further identifies a causal relationship between human trafficking and migration. My main findings are i) migrant networks, proxied with migrant stocks of a specific source country, increase human trafficking inflows, measured by the numbers of victims and perpetrators, from that respective country; and ii) the positive network effect on human trafficking decreases as income level increases. The first finding suggests two possible mechanisms of channeling network effects on human trafficking: pulling low-skilled migration in source countries by lowering informational costs on migration (supply side) and increasing demand for sex services provided by victims in migrant society in the destination country (demand side). The second finding indicates that the positive network effect is generated on the supply side in source countries, as people in lower income source countries are more susceptible to lower migration costs and therefore more likely to be moved by migrant networks in the destination (Mckenzie and Rapoport 2007). 
My study contributes to the migration literature by identifying migrant networks as a pull factor of human trafficking. The findings of this paper imply that existing (legal) migration may lead to a negative outcome of inducing the illicit, exploitative migration form of human trafficking - adding to the findings of Pedersen et al. (2008) that suggest the positive outcome of migrant networks on further migration.

This paper continues as follows. Section 2 describes the trends and patterns of human trafficking in Germany. Section 3 presents the data on human trafficking used for my empirical analysis. Section 4 discusses the estimation model, followed by the empirical findings in section 5. Section 6 concludes with some policy implications.

\section{Human Trafficking in Germany}

According to the United Nations, Germany is one of the major destinations for human trafficking victims together with the United States and several other Western European countries such as the Netherlands, Belgium and Italy (UNODC 2006). Since 2001, more than eight thousand victims of human trafficking have been identified by the German Federal Criminal Police Office (BKA). Figure 1 shows the numbers of victims identified in Germany during the period between 2001 and 2010. In 2001, 987 victims were identified and this number increased to 1,235 in 2003 . There are two mains reasons for this increase. Firstly, in 2003, the BKA started including domestic victims, consequently 127 German nationals were newly included in the total number of victims for that year. Secondly, the number of victims from Russia and Romania increased sharply: 143 in 2002 to 317 in 2003 and 47 in 2002 to 143 in 2003, respectively. In 2004, the number of identified victims decreased to 972 as the number of Eastern European victims, including Russians, decreased: from 988 in 2003 to 734 in 2004. In the recent years (2005-2010), the annual number of identified victims seems to have stabilized between 610 and 775 .

The majority of victims originate from Europe (see figure 2). In 2010, 85.2\% (520) of the total number of victims are from Europe. Among the European victims, Eastern European and the former Soviet countries form the largest group. In 2002, $87 \%$ (708) of the total number of victims come from these countries (i.e. Bulgaria, Estonia, Serbia, Latvia, Lithuania, Moldova, 
Poland, Romania, Russia, Slovakia, Slovenia, Czech Republic, Ukraine, Hungary, and Belarus). The proportion of Eastern Europe and former Soviet countries has recently decreased and, in 2010 , approximately $60 \%$ of all the victims originated from this group of countries. The rest of the European victims are mostly Germans and Turkish. Outside Europe, Thailand and Nigeria tend to contribute a considerable number of victims.

Figure 3 shows the distribution of identified victims by source country income levels based on the World Bank classifications. Until 2005, low-middle income countries (per capita annual income between 1,026 and 4,035 US dollars) were the major sources that sent victims to Germany, while in the recent years (2006-2010), the upper-middle income countries (per capita annual income between 4,036 and 12,475 US dollars) have formed the largest groups. This change is mainly because the major source countries in Eastern Europe keep providing victims despite recent increases in their income levels. Interestingly, the proportion of victims from low-income countries (per capita annual income below 1,025 US dollars) is rather minimal (between approximately 5-15\%) and has declined in recent years. Since 2006, a small portion of victims from high income countries (per capita annual income higher than 12,476 US dollars) have been identified - mainly from Czech Republic, Italy, and Greece. ${ }^{2}$

Figure 4 shows the distribution of migrant stocks in Germany by source-country income levels and suggests a plausible explanation to the question, why the majority of victims come from middle income countries (instead of low income countries). The descriptive statistics shown in figures 3 and 4 clearly indicate a positive association between the two. The dominance of middle income countries in migration corresponds with the distribution pattern of victims by income levels. In the following sections, I will empirically analyze whether migrant stocks have a causal effect on human trafficking.

\section{Data}

Data on human trafficking is hard to collect because human trafficking is a clandestine crime and therefore the magnitude of the crime is difficult, if not impossible, to gauge. Another

\footnotetext{
${ }^{2}$ German victims that comprise the largest part of the nu mber of victims from high income countries are excluded in this figure.
} 
difficulty in data collection arises with respect to various definitions of human trafficking. The definition of human trafficking is often confused with smuggling, illicit migration in general, and labor exploitation. Such variations in the definition of human trafficking make cross-country comparison of the data particularly problematic (Kangaspunta 2003).

In order to obtain reliable data on human trafficking, I make use of the statistics collected by the German Federal Criminal Police Office (BKA) which contain annual numbers of victims identified in Germany and traffickers investigated by the German police. The BKA has published the National Situation Report on Trafficking in Human Beings (Lagebild Menschenhandel) every year since 1999. ${ }^{3}$ The annual reports include detailed information on victims of human trafficking and their perpetrators (e.g. their nationalities, age, sex, etc.), thus providing an outlook on the inflows of human trafficking into Germany. The statistics provided by the BKA have several advantages for empirical research.

First, the data are collected based on the definition of human trafficking prescribed in the German Penal Code (section 232 for sex trafficking and section 233 for labor trafficking), which conforms with the international definition adopted by United Nations in the Protocol to Prevent, Suppress and Punish Trafficking in Persons, Especially Women and Children (2000). This definition consists of three main components of human trafficking - acts (recruiting and transferring human beings), means (by the means of threat or force), and purposes (exploitation). ${ }^{4}$ Thus, according to this definition, human trafficking is clearly distinguished from other types of illicit migration or crimes.

Second, the BKA statistics has provided annual variations in the number of victims of human trafficking and their perpetrators for more than 10 years. Such longitudinal data is rare in the data collection of human trafficking. The statistics with annual variations enables me to

\footnotetext{
${ }^{3}$ In this paper I use the data for the period of 2001-2010, excluding 1999 and 2000, because the migration statistics used to construct the main independent variable are available from 2001.

4 "Trafficking in persons" shall mean the recruitment, transportation, transfer, harbouring or receipt of persons, by means of the threat or use of force or other forms of coercion, of abduction, of fraud, of deception, of the abuse of power or of a position of vulnerability or of the giving or receiving of payments or benefits to achieve the consent of a person having control over another person, for the purpose of exploitation. Exploitation shall include, at a minimum, the exploitation of the prostitution of others or other forms of sexual exploitation, forced labour or services, slavery or practices similar to slavery, servitude or the removal of organs (article 3-a, Protocol).
} 
conduct a panel analysis controlling for unobserved heterogeneity of countries and time effects, which are crucial to estimating the determinants of human trafficking.

On the other hand, the BKA statistics are not completely free of drawbacks. Most importantly, the statistics provide reported numbers of human trafficking: victims identified and perpetrators investigated by the German police. Thus, the numbers are unlikely to capture the true magnitude of human trafficking in Germany but show a fragment of the problem only, resulting in underestimation. Furthermore, the police statistics not only reflect part of the prevalence of human trafficking but also the level of law enforcement against human trafficking. This problem is, however, mitigated by the fair assumption that the level of law enforcement by the German police should be constant in combating human trafficking originating from different source countries. In other words, the law enforcement of the German police against human trafficking from Russia is arguably equivalent to the law enforcement of the German police against human trafficking from Poland during the same period. However, this assumption can be challenged if the policy priority varies over time and the German police tackle human trafficking originating from a different source country each year. To reduce these problem the reported statistics encounter, I aggregate the numbers of victims and perpetrators during the period of investigation and take the average values - five-year and 10-year average, respectively.

In this paper, I use the number of identified victims and perpetrators of sex trafficking by their nationalities, excluding those of labor trafficking, because the statistics on labor trafficking in Germany are available only for 2008-2010 without identifying their nationalities. Given that sex trafficking is the most prevalent type of human trafficking worldwide (UNODC 2006) as well as in Germany (BKA 2010), this approach addresses the most serious form of human trafficking.

\section{Estimation Model}

Existing migrant networks may induce more human trafficking by pulling migration of the low-skilled. To estimate the network effect on human trafficking, potential determinants of human trafficking need to be modeled. The following equation provides a baseline specification 
on the factors of source-countries which affect the prevalence of human trafficking into destination - Germany.

$$
\begin{aligned}
& h_{i}=\beta_{1} m_{i}+\beta_{2} x_{i}+\beta_{3} Z_{i}+u_{i} \\
& p_{i}=\beta_{1} m_{i}+\beta_{2} x_{i}+\beta_{3} z_{i}+u_{i}
\end{aligned}
$$

$h_{i}$ is the number of victims from country i who are identified in Germany during the period of investigation. $p_{i}$ is the number of perpetrators from country $i$ who are investigated for committing crimes of human trafficking in Germany during the period. The number of perpetrators is included as a dependent variable in addition to the number of victims because traffickers tend to target their own nationals for human trafficking, thus the number of perpetrators can be used as an indicator for the prevalence of human trafficking from that respective country. $m_{i}$ is the (logged) stock of migrants - male, female, and total migrants, respectively - from country i, who reside in Germany during the time. This variable reflects migrant network effects. The data on victims and perpetrators are taken from the German Federal Criminal Police Office (BKA, 2001-2010) and the data on migration are from the German Federal Statistical Office (2011). Vector $X_{i}$ is a set of variables capturing source-country characteristics and conditions pushing people out of their countries for human trafficking. Vector $Z_{i}$ is a set of variables which relate to pull factors inducing human trafficking into German from country i. $u_{i}$ is the idiosyncratic error term. Robust standard errors are applied in order to control for potential heteroscedasticity. In this baseline model, I use the aggregate numbers of victims during the period of 2001-2010 in order to mitigate the problems of fragmented and reported statistics of human trafficking (see section 3 ). This cross-sectional analysis covers up to 151 countries $(i=1,2, \ldots, \ldots, \ldots, 151)$.

However, the cross-sectional analysis is subject to omitted variable biases because the model does not allow controlling for unobserved country-heterogeneity which may critically affect human trafficking flows into Germany. Furthermore, time effects are also not taken into account in this estimation. To address these issues, a panel analysis is further employed by taking the following form. 


$$
\begin{aligned}
& h_{i t}=\alpha_{i}+\beta_{1} m_{i t}+\beta_{2} X_{i t}+\beta_{3} z_{i t}+t+u_{i} \\
& p_{i t}=\alpha_{i}+\beta_{1} m_{i t}+\beta_{2} x_{i t}+\beta_{3} z_{i t}+t+u_{i} \\
& (i=1,2, \ldots,, 151),(t=1,2,, \ldots,, 10)
\end{aligned}
$$

$h_{i t}$ is the number of victims from country $i$ who are identified in Germany in year $t . p_{i t}$ is the number of perpetrators from country $i$ who are investigated for committing crimes of human trafficking in Germany in year t. $m_{i t}$ is the (logged) stock of migrants (male, female and total migrant populations, respectively) from country $\mathrm{i}$, who reside in Germany during the time (t). Vector $X_{i t}$ is a set of variables capturing source-country push factors and $Z_{i t}$ is a set of pull factors. $\alpha_{i}$ captures effects of time-invariant country heterogeneity. $t$ is a year dummy reflecting time effects and $u_{i t}$ is the idiosyncratic error term. Again, in all the regressions, robust standard errors are used. In the panel analysis, I take the five-year average values of the variables in order to mitigate the fragmented and reported nature of the data. Taking the five-year average value of migrant stocks also takes into account that the effect of migrants on human trafficking may not be contemporary and it takes time for migrant networks to induce human trafficking. Additionally, I run panel regressions with annual variations including both contemporary and lagged values migrant stocks as check for robustness (see section 5.3).

In both cross-sectional and panel estimations, various push and pull factors of human trafficking are controlled for. Vector $X_{i t}$ includes economic, institutional, and social factors pushing potential victims to be trafficked out of their countries. (Logged) per capital income is controlled for because most victims are initially migrants seeking better economic opportunities elsewhere and therefore the income level is a crucial determinant affecting the decision of potential victims to take risks of insecure migration (Akee et al. 2010 a, b; Cho 2012; Jakobsson and Kotsadam 2011). The level of corruption - the control of corruption - is included because corruption deteriorates the institutional quality of a country, thus harming the life quality of its people. Furthermore, the corruption of government officials makes institutional environments more favorable for human traffickers to operate their exploitative, illicit human trade (Bales 2007; Cho 2012; Cho et al. forthcoming; Mahmoud and Trebesch 2010). The level of female education - female gross enrollment rates in secondary schools - is also included 
because the majority of victims of human trafficking are females and their lack of opportunities is an important push factor for women and girls to take risks which might result in their being trafficked (Rao and Presenti 2012). The income and education data are taken from the World Development Indicator (2011). For the control of corruption, Kaufmann et al.'s (2009) data are used.

Vector $Z_{i t}$ includes a list of pull factors inducing trafficking flows into Germany. Trade in goods and services may facilitate human movements between countries (Danailova-Trainor and Belser 2006) and thus bilateral trade between Germany and a source country - data taken from the United Nations Commodity Trade Statistics Database (2012) - is included as a pull factor. Membership of the Schengen Agreement (1985) - ensuring free human movements inside the Schengen area which currently consists of 26 European countries including Germany - is also included in order to control for the impact of border control on international travelling. Membership of the Schengen Agreement is used instead of visa restrictions in entering Germany because many victims are smuggled via neighboring countries, which function as transit places for human trafficking into Germany. Thus, free movements across neighboring countries are more crucial to this type of human transactions (see BKA 1999-2010). Also, informational exposure via TV and other media is included, as the media can pull people out of their country by providing them with information about the outside world (Cho 2012; Cho forthcoming; Mahmoud and Trebesch 2010; Mo 2011). The percentage of internet users, TV, and trade in newspapers - data taken from the KOF Globalization Index (Dreher 2006) - is used as a proxy to the level of the informational exposure. In addition, geographical proximity to Germany can be an important pull factor for the transferring and smuggling of humans into Germany. With this respect, (logged) distance between Germany and the source country distance between the two capital cities, data taken from PRIO GRID (Tollefsen et al. 2012) - and the regional dummy variable being Europe and Central Asia - following the World Bank classification - are controlled for. The descriptive statistics of the data used are provided in appendix $A$. 
The empirical models presented above are designed to estimate the aggregate impact of migrant networks on human trafficking into Germany. However, migrant networks may induce human trafficking via two different mechanisms: one from the supply side and the other from the demand side. On the supply side, migrant networks may reduce informational costs of migration pulling migrants with low skills and, as a result, enlarge the pool of potential victims of human trafficking. On the demand side, migrant networks may increase demand for sexual services provided by their own people in the destination country. Unfortunately, there is neither data on the educational level of migrants nor data on such demand for prostitution to single out the different effects. Alternatively, I construct an interaction term between the income level of source country $i$ and the migrant stocks from country $i$ who reside in Germany in order to gauge effects from the supply side. ${ }^{5}$ The motivation behind this approach is as following. On the supply side, migrant networks arguably pull human trafficking because the networks increase the pool of low-skilled migration by reducing informational costs on migration. This effect, however, may vary across different levels of income because of two reasons. Firstly, changes in marginal propensity to migrate, caused by changes in informational costs, may be different depending on income level. For instance, people in a higher income country may find information provided by migrant networks less valuable that those in a lower income country, because there are more available alternative informational sources in higher income countries. Secondly, there are more low-skilled people in lower income countries and therefore the pool of potential low-skill migrants, who can be pulled out, is greater in lower income countries than higher income countries. With this in mind, theory predicts that the network effect on human trafficking decreases with the level of income, if the migrant networks pull victims of human trafficking by lowering informational costs. Thus, in this model, a significant interaction effect arguably reflects how migrant networks affect migratory decisions of victims on the supply side of human trafficking.

\footnotetext{
${ }^{5}$ The interaction effect may also suggest the impact of migrant networks from the demand side if the income level of a source country is positively correlated to the needs of migrants for sex services in the destination. However, there is no empirical evidence that the income level of the country of origin is endogenous to such needs in the destination country.
} 
Equation 3 and 3 ' below include the interaction term between the income level and the stocks of migrants denoted as $\mathrm{m}_{\mathrm{it}} \mathrm{g}_{\mathrm{it}}$. The other notations are identical to those in equation 2 and $2^{\prime}$.

$$
\begin{aligned}
& h_{i t}=\alpha_{i}+\beta_{1} m_{i t}+\beta_{2} x_{i t}+\beta_{3} z_{i t}+\beta_{4} m_{i t} * g_{i t+} t+u_{i} \\
& p_{i t}=\alpha_{i}+\beta_{1} m_{i t}+\beta_{2} x_{i t}+\beta_{3} z_{i t}+\beta_{4} m_{i t} g_{i t} t+u_{i} \\
& (i=1,2,, \ldots,, 151),(t=1,2,,,,, 10)
\end{aligned}
$$

\section{Empirical Results}

\subsection{Baseline Model and Econometric Specification}

Table 1 shows the results of the cross-sectional analysis. Given that the dependent variable is a count variable with nonnegative integer values $\{0,1,2 \ldots$.$\} , a liner model may not$ provide the best fit over all values of the explanatory variables. Thus, expected values are modeled to take the form of exponential functions as below (see pp.546-547, Wooldridge 2008).

$$
E\left(y \mid x_{1}, x_{2},, x_{k}\right)=\exp \left(\beta_{0}+\beta_{1} x_{1}+\ldots+\beta_{k} x_{k}\right)
$$

As this model is nonlinear in its parameters, a maximum likelihood analysis of the negative binomial regression model is employed here. The negative binomial maximum likelihood estimation is more efficient than the Poisson quasi-maximum likelihood method, given the assumption that there cannot be underdispersion (see pp.657-659, Wooldridge 2002). In addition to the negative binomial regressions, I also conduct a linear analysis in order to show the robustness of the results.

The results in table 1 show that migrant networks increase the number of human trafficking victims and their perpetrators and the finding is robust to the different measurements of the networks (migrants, male migrants, and female migrants). The coefficients are statistically significant at $1 \%$ level in the non-linear model, while the significance level is $10 \%$ in the linear model. Regarding the control variables (see column 1-6), control of 
corruption reduces the number of victims, but the effect does not turn out to be significant for perpetrators. Female education reduces human trafficking - both the numbers of victims and perpetrators, while bilateral trade with Germany increases human trafficking. A higher income level reduces the number of victims but it does not have a significant effect on traffickers. Informational exposure to the outside world increases human trafficking but the coefficients are mostly insignificant. Geographical effects are also found here. Distance between the source country and Germany decreases human trafficking, while being in Europe/Central Asia increases the prevalence of the crime. However, in the liner model (column 7-12), the coefficients of most control variables lose their statistical significance, except the membership of the Schengen agreement, which turns out to be significant and negative.

The cross-sectional analysis, however, does not capture unobserved country-specific heterogeneity and time-specific effects, which may be important to human trafficking flows into Germany. Thus, I make the use of the longitude data with time-variations and conduct a panel analysis. The unobserved effect $-\alpha_{i}$ in equation $2,2^{\prime}, 3$, and $3^{\prime}-$ is treated as either a random effect or a fixed effect, depending on whether or not $\alpha_{i}$ is uncorrelated with the observed explanatory variables (see pp.251-252, Wooldridge 2008). To test for $\operatorname{Cov}\left(\alpha_{i}, x_{i t}\right)=0$, the Hausman test is conducted under the null-hypothesis below.

Ho: difference in coefficients not systematic

$$
\text { chi2 }=(b-B)^{\prime}\left[\left(V_{-} b-V_{-} B\right)^{\wedge}(-1)\right](b-B)
$$

( $b=$ consistent under $\mathrm{Ho}$ and $\mathrm{Ha}$; $\mathrm{B}=$ inconsistent under $\mathrm{Ha}$, efficient under $\mathrm{Ho}$ )

The result shows that the Hausman test fails to reject the null-hypothesis with p-value 0.41 for $h_{i t}$ and 0.94 for $p_{i t}$. Given the result, the random effect is more efficient than the fixed effect and therefore this method is selected for the panel analysis.

\subsection{Aggregate Results}

Table 2 presents the results of the panel estimations with random effects. The panel data take five-year average values, as described in section 4 , and therefore, the dependent variable is not a count variable anymore. Thus, the linear model is the preferred estimation 
method here. In addition to that, the negative binomial method is also applied, taking into account that the dependent variable is non-negative. Column (1)-(6) show the results of the linear estimations. Migrant networks have positive effects on human trafficking and the effects are significant at $5 \%$ level, except male migration on perpetrators at $10 \%$. In the non-linear model (column 7-12), the network effects are significant at $1 \%$ level for perpetrators, while the statistical significance of the effects is $10 \%$ level for victims.

Quantitatively, the magnitudes of the network effects are larger for victims than perpetrators. ${ }^{6}$ Specifically, a $10 \%$ increase in migrant stocks increases the number of victims by $7.9 \%$, while the same change leads to an increase in the number of perpetrators by $6.4 \%$. Interestingly, the effect of male migrant networks is smaller than that of female networks. A $10 \%$ increase in male migrant networks increases the number of victims by $7.6 \%$ and that of perpetrators by $6.6 \%$, while the same change in female migrant networks leads to increases in the numbers of victims and perpetrators by $9.2 \%$ and $7.3 \%$, respectively. This result seems to suggest that the network effect on the supply side is dominant over the effect on the demand side because the stocks of male migrants can be a (rough) proxy to demand for sexual services provided by victims, while female migrant networks generally function as informational sources which pull victims to migrate from source countries. ${ }^{7}$ A greater role of female migrant networks in information provision is plausible, given that the majority of victims are women and girls (see BKA 1999-2010) and it is generally assumed that people tend to maintain stronger contact with others of the same sex. However, the stocks of migrants by sex are rough proxies to information and demand, non-exclusive to each other. In section 5.3, I will present additional empirical evidence supporting the network effects on the supply side.

Turning to the control variables, the coefficients of most variables lose their statistical significance in the linear model after controlling for unobserved heterogeneity and time effects, except the positive effect of the dummy variable, being Europe and Central Asia. However, several effects are still significant in the non-linear model. Control of corruption reduces human

\footnotetext{
${ }^{6}$ Quantitative interpretation is given based on the results of the linear estimations.

${ }^{7}$ Male migrants can also be informants who encourage victims to migrate and thus network effects of male migrants do not reflect the demand exclusively but a mixture of information and demand. On the other hand, the extent that female migrants create demand for prostitution services is generally minimal.
} 
trafficking, while transactions of goods and services with Germany (bilateral trade) increase the illicit, exploitative human transactions. Also, being far away from Germany (distance) reduces the probability of human trafficking occurring.

\subsection{Income Level of Source Countries and Interaction Effects}

The results above show that migrant networks pull human trafficking into Germany. In order to find whether or not the network effect exists on the supply side in origin countries of victims, I include an interaction term between the stocks of migrants and the income level of the source country in the estimation model (see section 4).

Table 3 presents results including the interaction term. Column (1)-(6) show the results of the linear estimation. The network effects are positive at $10 \%$ level of the significance and the effects decline as income arises with respect to the number of victims. On the other hand, the effect on perpetrators loses its statistical significance by including the interaction term. The results of the negative binomial estimations also support the significant but decreasing effects of migrant networks in income level (column 7-8). In this case, the result holds for both victims and perpetrators. Using male and female migrant stocks (column 9-12) instead of total migrants, the network effects are positive and statistically significant at 5-10\%, while the negative interaction effect is statistically significant only for the combination of perpetrators and female migrants (column 12). In the other estimations (column 9-11), the interaction term marginally loses its significance. Generally speaking, the interaction effect is more pronounced for victims than perpetrators, probably because reduction in informational costs affects victims' decision to migrate rather than perpetrators' decision to commit a crime.

A graphical demonstration can more clearly present how the marginal effect of migrant networks on the number of victims varies across different levels of income (Greene 2010). Figure 5 shows that the marginal effect declines as income level arises. The network effect is evident for low and middle income countries but practically irrelevant to high income countries, as the statistical significance of the network effect disappears when the income level reaches approximately 8,000 US dollars (the income level of Croatia in 2004) or higher. 
Finally, I further conduct panel analysis with annual variations in order to check for the robustness of my findings. In doing so, I use both contemporary and lagged values of migrant stocks, taking into account that the network effect on human trafficking may not necessarily be contemporary but it is likely to take some time to be generated. ${ }^{8}$ Table 4 shows the results of the panel analysis with random effect. Column (1)-(6) confirm the positive effects of migrant networks and decreasing effect of the networks in income. Taking the lagged values of migrant stocks does not alter the main findings (column 7-12). Additionally, table 5 shows the results of the estimations with fixed effect. Given the result of the Hausman test, the fixed effect analysis is not efficient and likely undermines the network effects. However, the positive network effect and the negative interaction effect survive in most regressions, rigidly controlling for two-way country and time fixed effects. By using the contemporary values of migrant stocks, the effects hold for perpetrators, while they lose statistical significance for victims marginally - around $12 \%$ level (column 1-6). However, the main findings hold for both victims and perpetrators when employing the lagged values of migrant stocks (column 7-12) - the preferred estimation method over the one with the contemporary values.

\section{Conclusion}

By employing the longitude data on victims and perpetrators of human trafficking into Germany during the period of 2001-2010, this paper empirically shows that the migrant networks increase human trafficking. It further presents that the network effect decreases as the income of a source country increases. The declining network effect in income suggests that migrant networks pull victims of human trafficking by increasing low-skilled migration due to the reduction in informational costs on migration. The main findings are robust to different estimation methods (linear and non-linear estimations and random and fixed effects), data variations (10-year average, five-year average and annual values), and various measurements of human trafficking (the numbers of victims and perpetrators) and proxies to migrant networks (total, male, and female migrant stocks and contemporary and lagged values of the stocks).

\footnotetext{
${ }^{8}$ Also, victims are not always immediately identified by police upon their arrival in the destination country. The ILO estimates that the duration of exploitation of victims is about a year (ILO 2012), justifying the application of the lagged value.
} 
The findings of my paper indicate an unwanted consequence of migration - i.e. migrant networks mostly consisting of legal migrants can be a pull factor inducing an illegal, exploitative migration form of human trafficking. However, my study does not claim that close door-policy restricting migration per se should be a solution for combating human trafficking. Instead, my findings alert policy makers that migration policy should address anti-trafficking interventions together, particularly when the country receives a large scale of low-skilled migration. 


\section{References}

Akee, Randall, Arjun Bedi, Arnab K. Basu and Nancy H. Chau. 2010(a). Transnational Trafficking, Law Enforcement and Victim Protection: A Middleman's Perspective. Mimeo, Cornell University.

Akee, Randall, Arnab K. Basu and Nancy H. Chau and Melanie Khamis. 2010(b). Ethnic Fragmentation, Conflict, Displaced Persons and Human Trafficking: An Empirical Analysis, in Gil S. Epstein, Ira N. Gang (eds.), Migration and Culture (Frontiers of Economics and Globalization, Volume 8). Emerald Group Publishing Limited.

Bales, Kevin. 2007. What Predicts Human Trafficking? International Journal of Comparative and Applied Criminal Justice 31(2): 269-279.

Cho, Seo-Young. 2012. Modelling for Determinants of Human Trafficking. Economics of Security Working Paper No. 70, Berlin.

Cho, Seo-Young. Forthcoming. Integrating Equality - Globalization, Women's Rights, and Human Trafficking. International Studies Quarterly (in press).

Cho, Seo-Young, Axel Dreher and Eric Neumayer. Forthcoming. Does Legalized Prostitution Increase Human Trafficking? World Development (in press)

Danailova-Trainor, Gergana and Patrick Belser. 2006. Globalization and the Illicit Market for Human Trafficking: an Empi rical Analysis of Supply and Demand. ILO Working Paper No. 78, Geneva.

Dreher, Axel. 2006. Does Globalization Affect Growth? Empirical Evidence from a new Index. Applied Economics 38(10): 1091-1110.

German Federal Criminal Police Office (Bundeskriminalamt, BKA). 1999-2010. Trafficking in Human Beings: National Situation Report (in German, Lagebild Menschenhandel), Wiesbaden.

German Federal Statistical Office (Statistisches Bundesamt). 2011. Data on Migration, Wiesbaden.

German Federal Government. 2005. German Penal Code (Strafgesetzbuch, StGB): section 232 and section 233, Berlin. 
Greene, William. 2010. Testing Hypotheses about Interaction Terms in Nonlinear Models. Economic Letters 107(2): 291-296.

International Labor Office (ILO). 2012. ILO Global Estimate of Forced Labour: Results and Methodology. ILO Special Action Programme to Combat Forced Labour, Geneva.

International Organization for Migration (IOM). 2010. Counter Trafficking Module (CTM), Geneva.

Jakobsson, Niklas and Andreas Kotsadam. 2011. The Law and Economics of International Sex Slavery: Prostitution Law and Trafficking for Sexual Exploitation. European Journal of Law and Economics (in press).

Jakobsson, Andreas and Niklas Kotsadam. 2012. The Economics of Trafficking for Sexual Exploitation. Draft, Norwegian Social Research and University of Oslo.

Kangaspunta, Kristiina. 2003. Mapping the Inhuman Trade: Preliminary Findings of the Database on Trafficking in Human Beings. Forum on Crime and Society 3 (1 and 2): 81103.

Kaufmann, Daniel, Kraay, Aart and Massimo Mastruzzi. 2009. Governance Matters VIII: Aggregate and Individual Governance Indicators 1996-2008. World Bank Policy Research Working Paper No. 4978, Washington DC.

Mahmoud, Toman Omar, and Christoph Trebesch. 2010. The Economic Drivers of Human Trafficking: Micro-Evidence from Five Eastern European Countries. Journal of Comparative Economics 38(2): 173-188.

Mckenzie, David and Hillel Rapoport. 2007. Network Effects and the Dynamics of Migration and Inequality: Theory and Evidence from Mexico. Journal of Development Economics 84:1-24.

Mo, Cecilia. 2011. Perceived Relative Poverty and Risk: An Aspiration-Based Model of Vulnerability. Working paper, Stanford University.

Palloni, Alberto, Douglas S. Massey, Miguel Ceballos, Kristin Espinosa and Michael Spittel. 2001. Social Capital and International Migration: A Test Using Information on Family Networks. American Journal of Sociology 106(5): 1262-1298. 
Pedersen, Peder J., Mariola Pytlikova, and Nina Smith. 2008. Selection and Network Effects Migration Flows into OECD Countries 1990-2000. European Economic Review 52:11601186.

Rao, Smriti and Christina Presenti. 2012. Understanding Human Trafficking Origin: A Crosscountry Empirical Analysis. Feminist Economics 18(2):231-263.

Schengen Agreement. 1985. Schengen.

Tollefsen, Andreas Forø, Håvard Strand and Halvard Buhaug. 2012. PRIO-GRID: A Unified Spatial Data Structure. Journal of Peace Research 49(2): 363-374.

Tyldum, Guri and Anette Brunovskis. 2005. Describing the Unobserved: Methodological Challenges in Empirical Studies on Human Trafficking in Frank Laczko (eds.), Data and Research on Human Trafficking: A Global Survey. International Organizations for Migration. Geneva.

United Nations (UN). 2000. Protocol to Prevent, Suppress and Punish Trafficking in Persons, especially Women and Children. New York.

United Nations (UN). 2012. Commodity Trade Statistics Database.

United Nations Office on Drugs and Crime (UNODC). 2006. Global Report on Trafficking in Persons. Vienna.

United States (US) Department of State. 2012. Trafficking in Persons Report. United States Department of State Publication, Washington DC.

Wooldridge, Jeffrey. 2002. Econometric Analysis of Cross Section and Panel Data. MIT Press.

Wooldridge, Jeffrey. 2008. Introductory Econometrics: A Modern Approach. Cengage Learning Emea.

World Bank. 2012. World Development Indicators. 
Figure 1. Total Numbers of (identified) Victims of Human Trafficking in Germany, 2001-2010

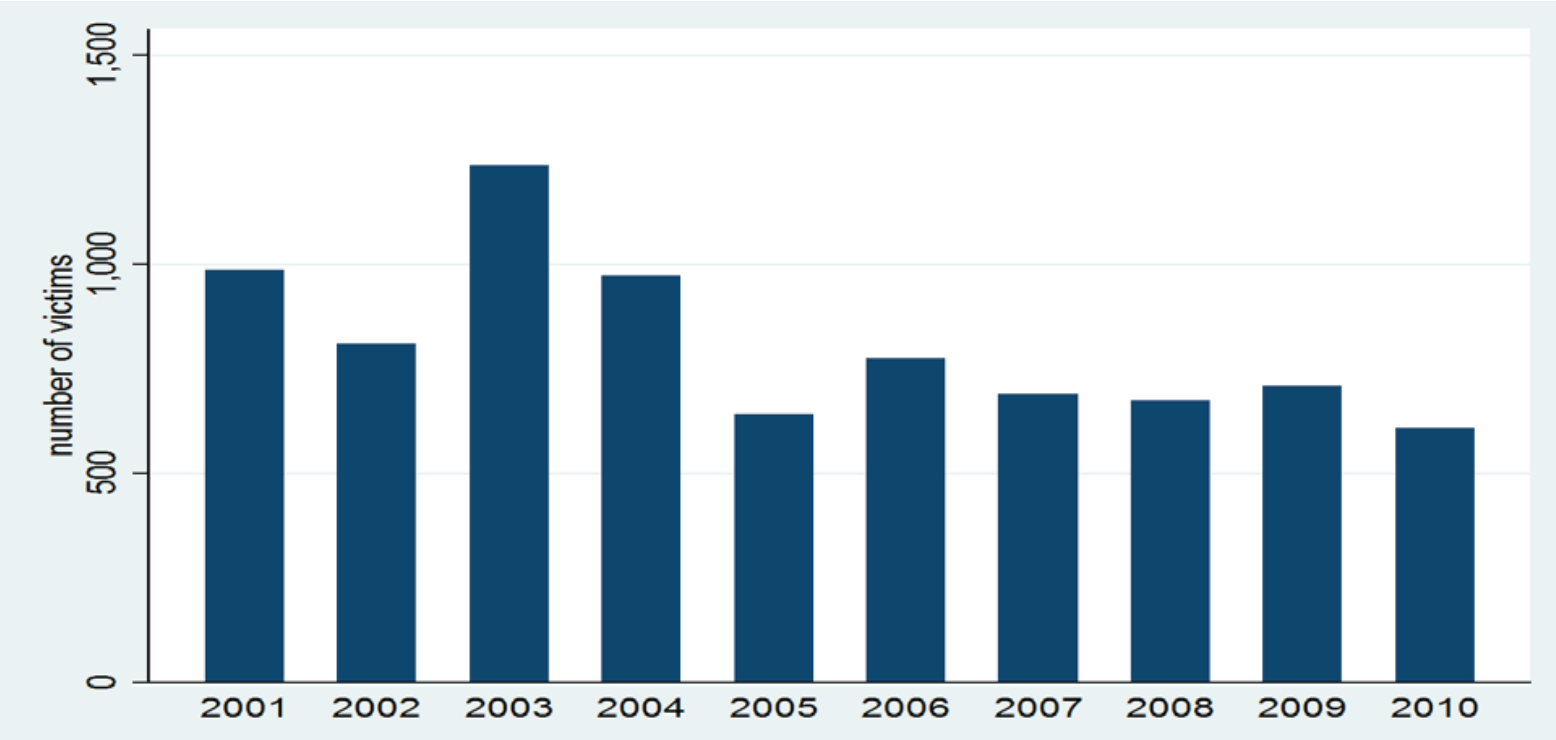

Source: German Federal Criminal Police Office (Bundeskriminalamt, BKA), 2001-2010

Figure 2. Victims of Human Trafficking in Germany, by source-country continents, 2001-2010

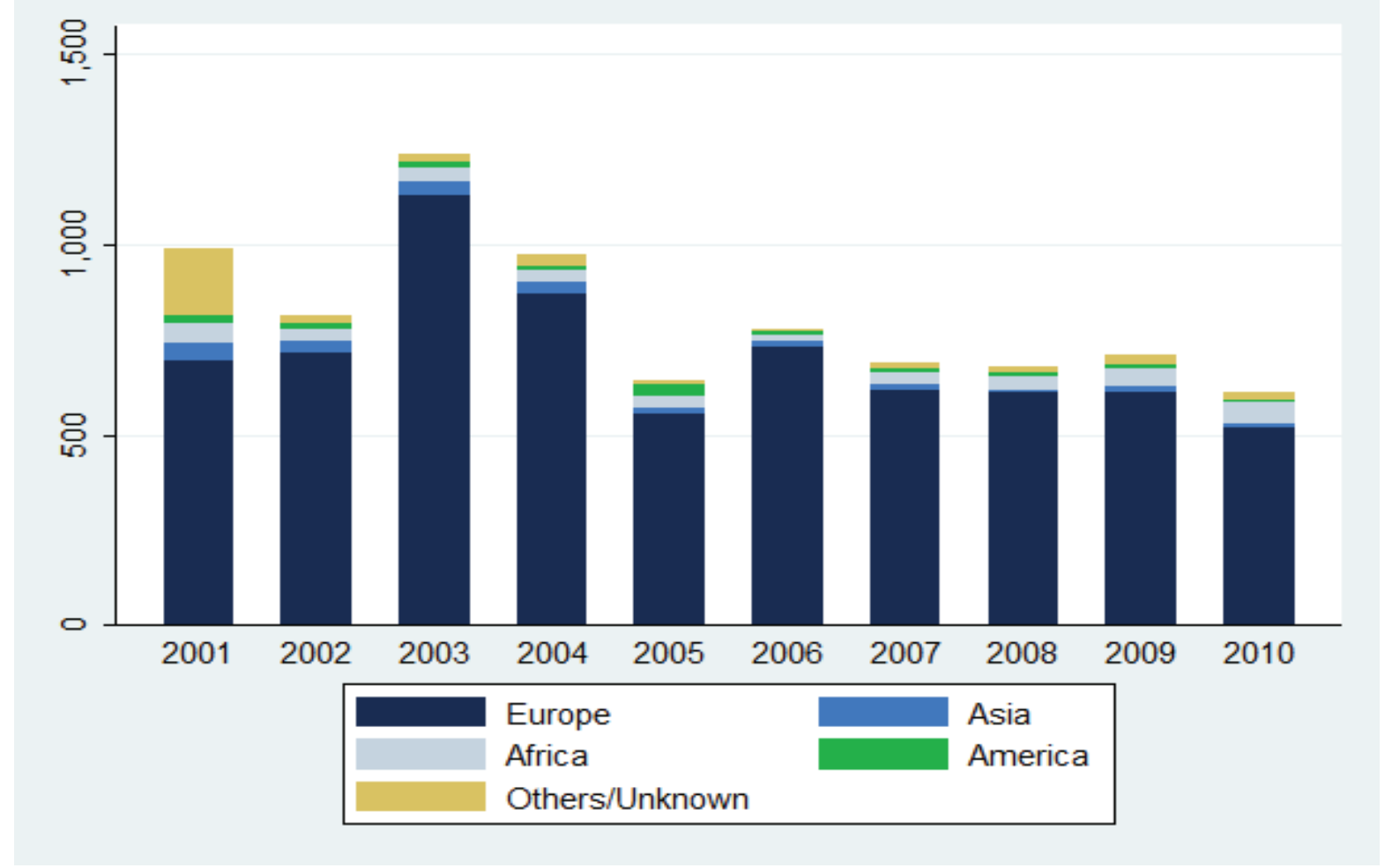

Source: German Federal Criminal Police Office (Bundeskriminalamt, BKA), 2001-2010 
Figure 3. Victims of Human Trafficking in Germany

by source-country income levels, 2001-2010

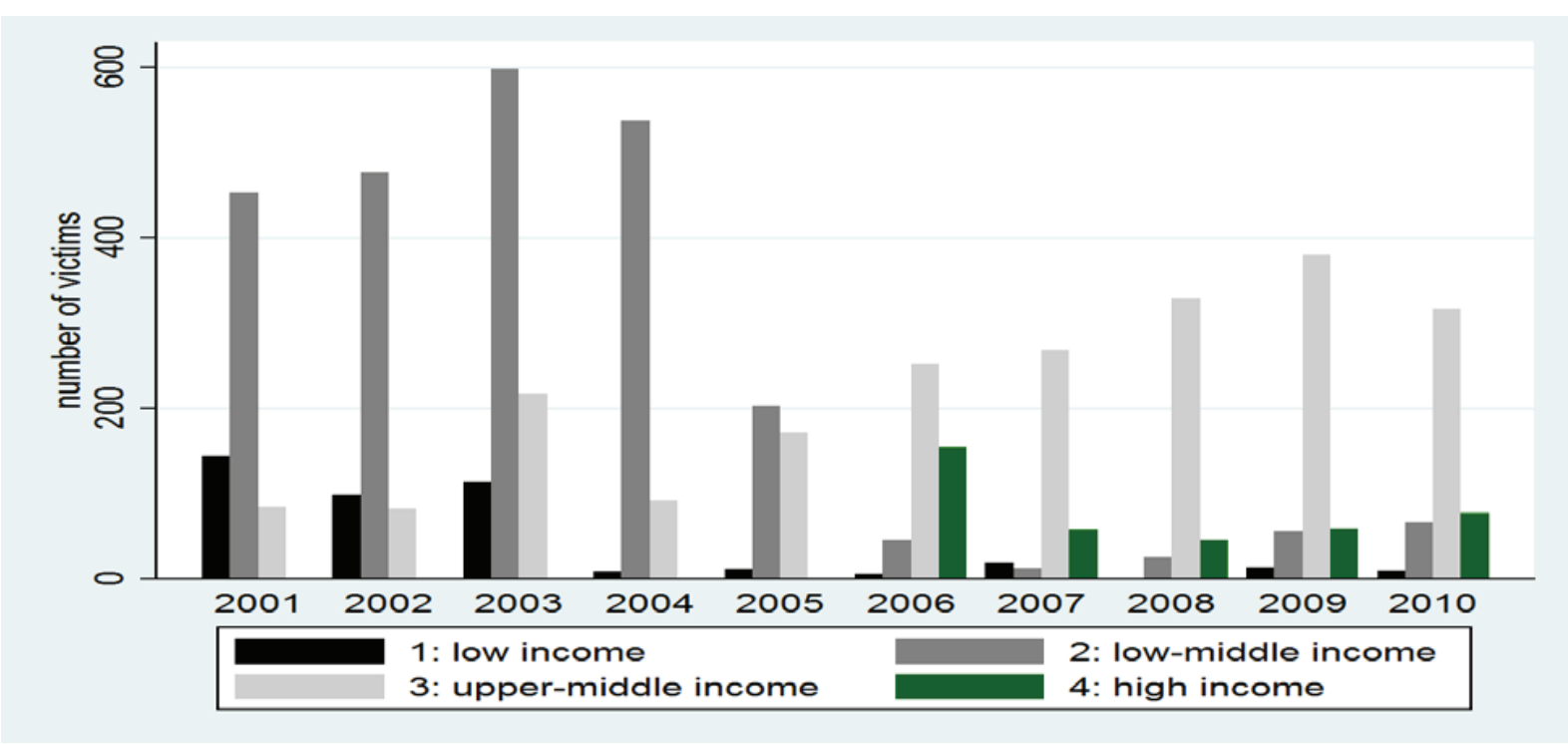

Source: German Federal Criminal Police Office (Bundeskriminalamt, BKA), 2001-2010.

Note: The numbers exclude victims with the German nationality.

Figure 4. Stocks of Foreign Populations in Germany

by source-country income levels, 2001-2009

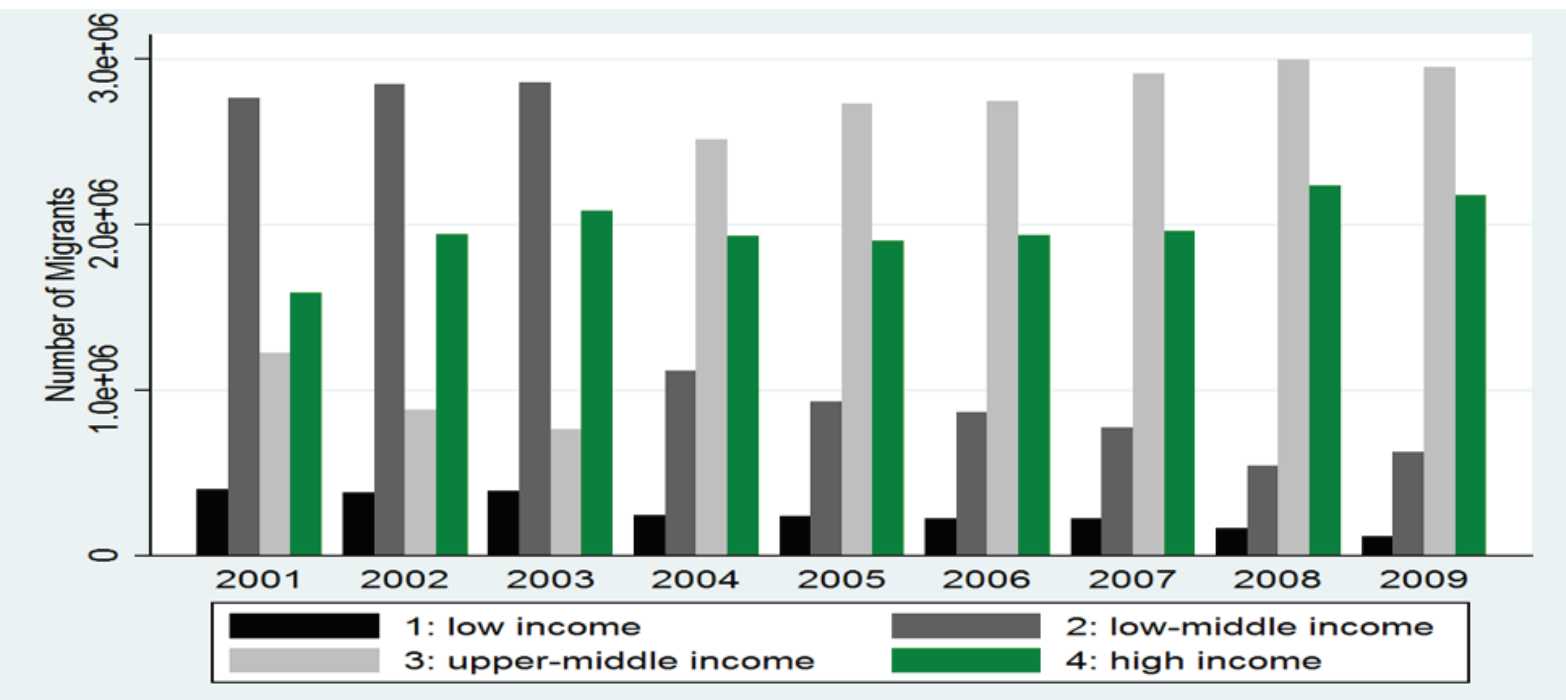

Source: German Federal Statistical Office (Statistisches Bundesamt), 2011.

Note: The numbers include 72 major source countries which the data covers. 
Figure 5. Marginal Effect of Migrant Networks on the Number of Victims in Different Income Levels

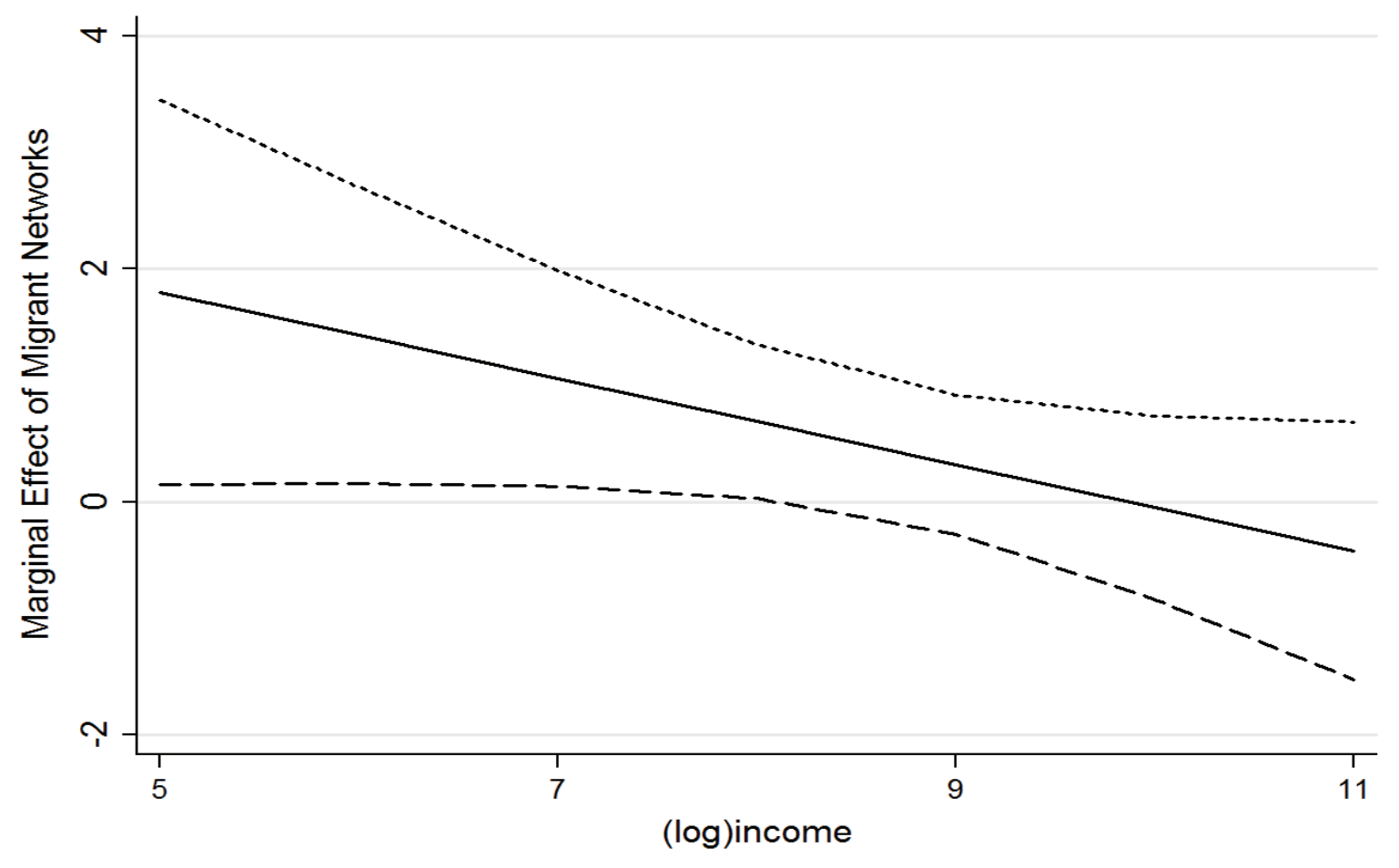




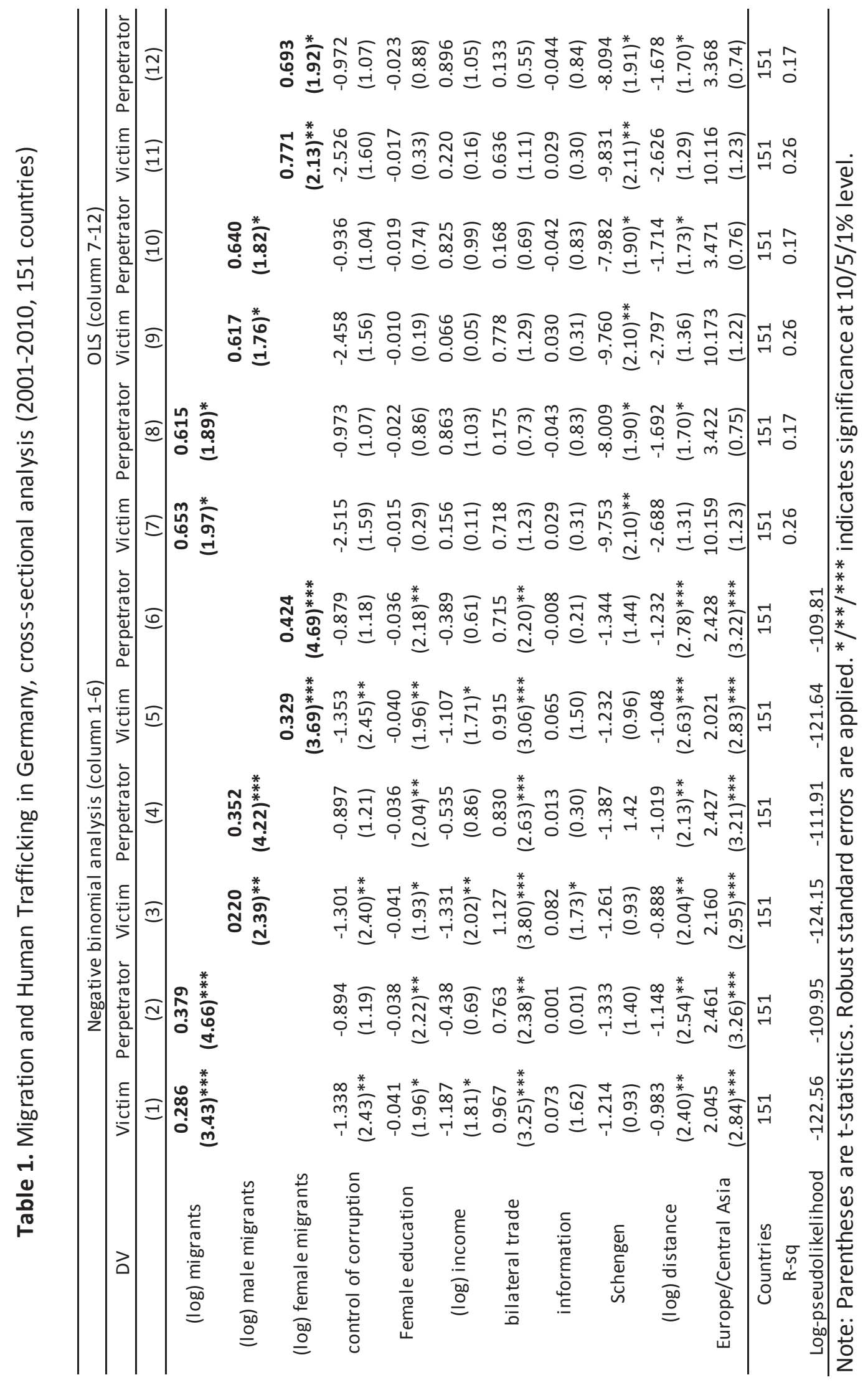




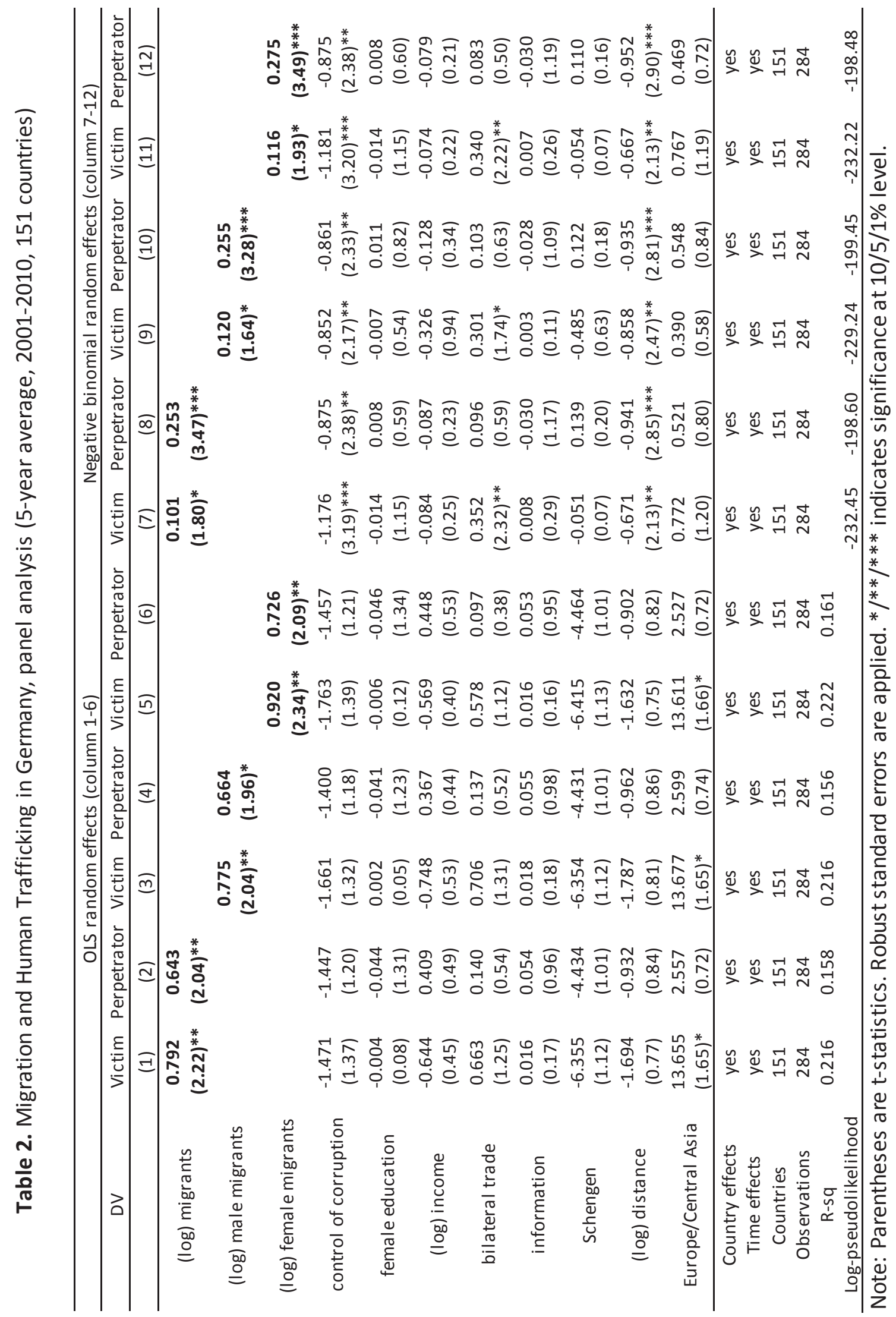




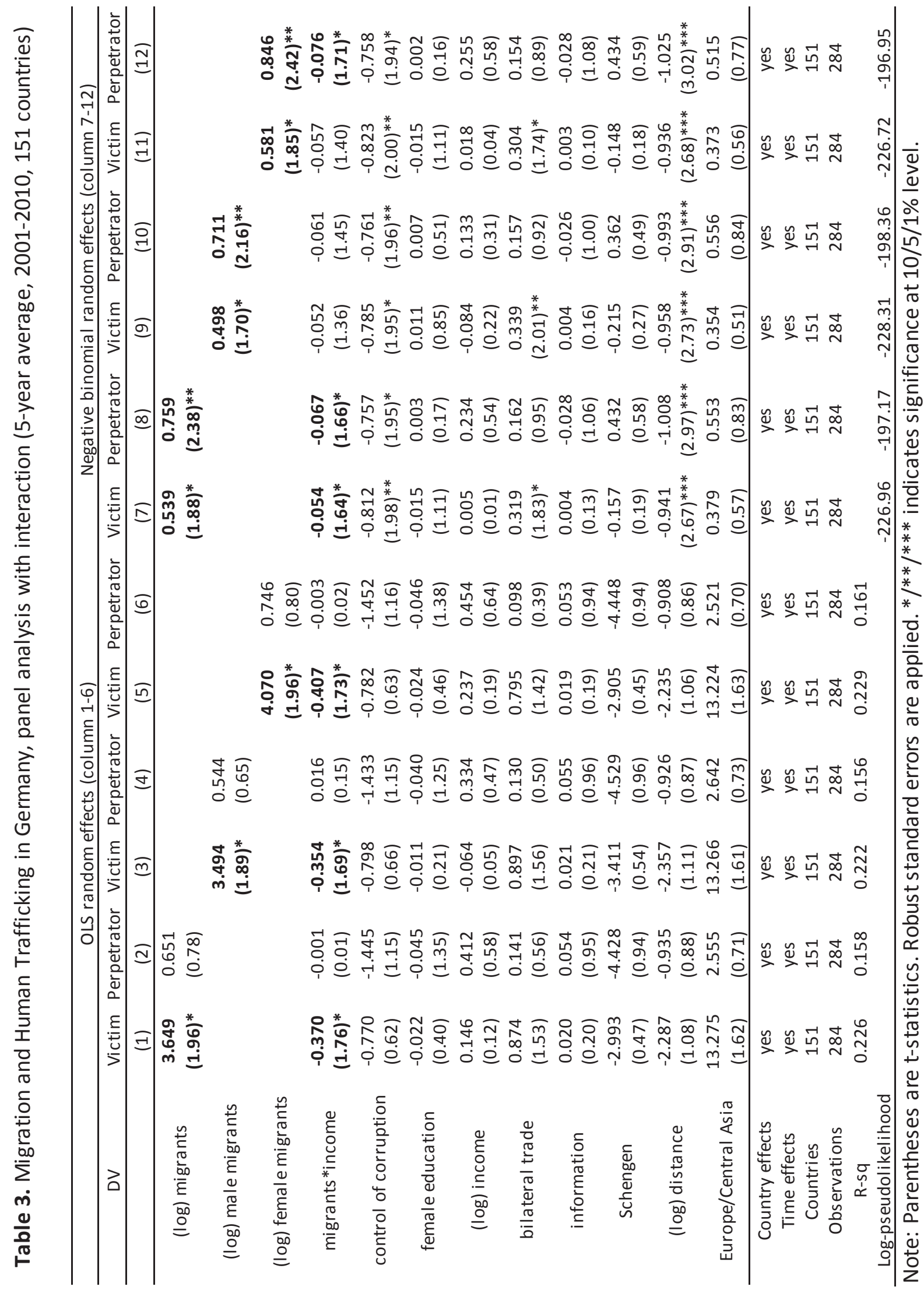




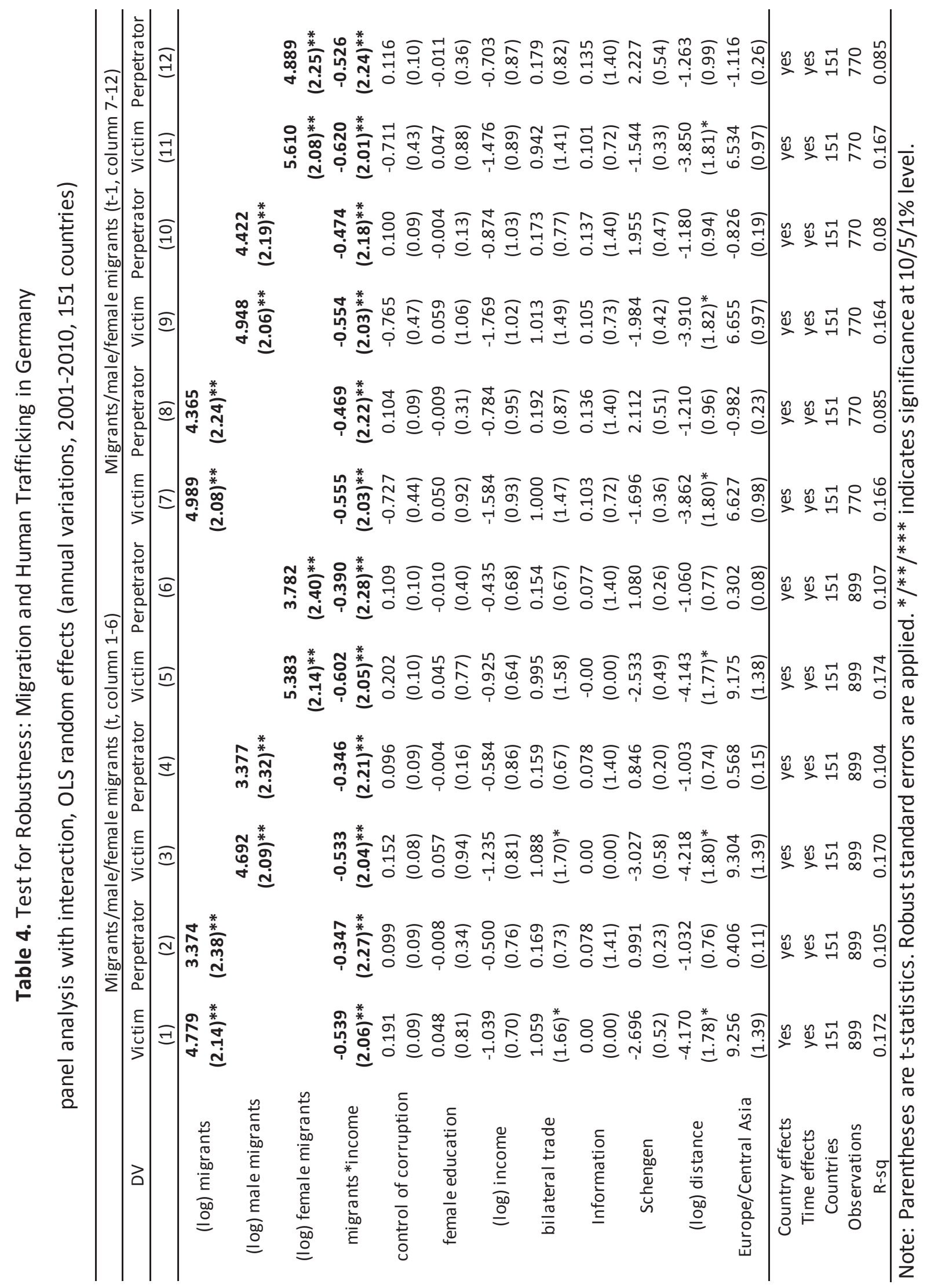




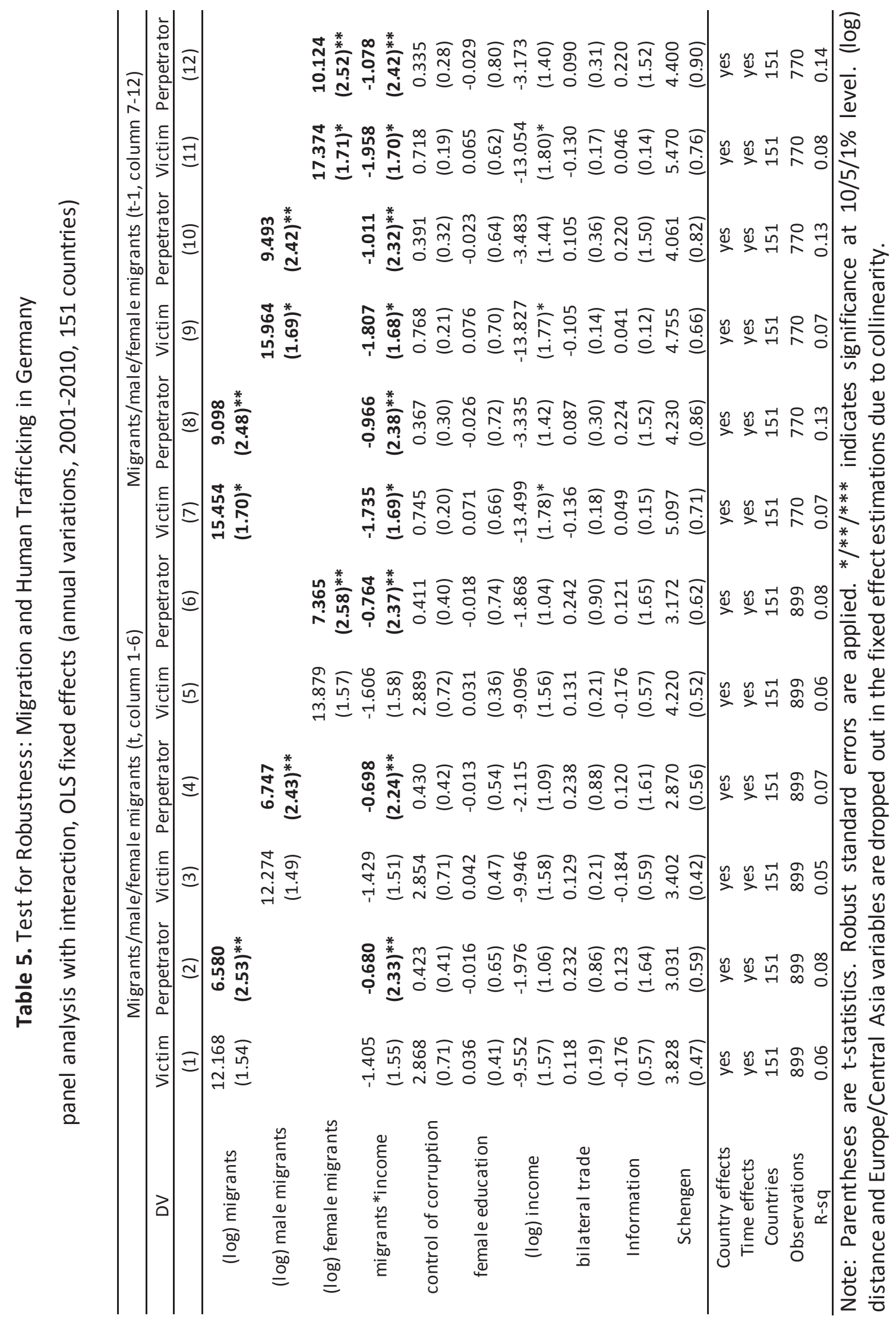


Appendix A. Descriptive Statistics

\begin{tabular}{cccccc}
\hline Variable & Observations & Mean & Std. Dev. & Min & Max \\
\hline number of victims & 899 & 4.322 & 21.640 & 0 & 317 \\
number of perpetrators & 899 & 2.113 & 10.537 & 0 & 149 \\
(log) migrants & 899 & 4.576 & 5.203 & 0 & 14.457 \\
(log) male migrants & 899 & 4.291 & 4.846 & 0 & 13.816 \\
(log) female migrants & 899 & 4.272 & 4.868 & 0 & 13.693 \\
control of corruption (index) & 899 & 0.043 & 0.995 & -1.546 & 2.625 \\
female education & & & & & \\
(enrolment rate in secondary school) & 899 & 74.319 & 32.965 & 4.935 & 168.336 \\
(log) income & 899 & 7.958 & 1.641 & 4.382 & 11.249 \\
(log) bilateral trade (export, dollars) & 899 & 19.853 & 2.707 & 10.878 & 25.591 \\
information (index) & 899 & 67.255 & 19.043 & 24.401 & 98.511 \\
Schengen (dummy) & 899 & 0.117 & 0.321 & 0 & 1 \\
(log) distance & 899 & 8.255 & 0.991 & 5.635 & 9.819 \\
Europe/Central Asia (dummy) & 899 & 0.170 & 0.376 & 0 & 1 \\
\hline
\end{tabular}

